\title{
OSTP as a novel peptide specifically targeting human ovarian cancer
}

\author{
CHEN YANG ${ }^{1,2}$, XIAOJUAN HE ${ }^{1}$, XIAOMIN LIU ${ }^{1}$, ZHENG TANG $^{3}$ and XIAOQIU LIANG ${ }^{1}$ \\ ${ }^{1}$ Cancer Research Institute, University of South China; ${ }^{2}$ Hunan Polytechnic of Environment and Biology; \\ ${ }^{3}$ First Affiliated Hospital, University of South China, Hengyang, Hunan 421001, P.R. China
}

Received April 8, 2015; Accepted May 29, 2015

DOI: 10.3892/or.2015.4066

\begin{abstract}
Ovarian cancer is a disease that seriously threatens the health of women and results in a high mortality rate. The present study aimed to investigate the novel peptide OSTP (peptide for specifically targeting ovarian cancer) to provide new methods for the effective diagnosis and treatment of ovarian cancer. The nude mouse ovarian cancer model was established. With the use of phage peptide display in vivo, a novel 7-amino peptide for specific binding to ovarian cancer was screened from the FliTrx bacterial peptide display system. OSTP was compounded and labeled with fluorescent pigment 5-FAM. The specificity and affinity of OSTP were tested in the ovarian cancer cell line A2780 in vitro. The tumortargeting assays of OSTP were performed in vivo by injecting 5-FAM-OSTP into tumor-bearing mice. Clinical tissue specimens were tested by fluorescence staining following the addition of 5-FAM-OSTP. We found that the peptide specifically bound to ovarian cancer A2780 cells. Cell fluorescence staining showed that 5-FAM-OSTP obviously and specifically bound to ovarian cancer A2780 cells, particularly to the cell membrane. One hour after i.v. peptide injection, 5-FAM-OSTP specifically targeted the tumor tissues in the tumor-bearing mice. In the human pathological sections, 5-FAM-OSTP exhibited strong specific binding to ovarian cancer tissues. The cell membrane and cytoplasm of the cells exhibited a fluorescent signal. This signal was more evident on the cell membrane. The present results suggest that OSTP is a potential strategy for the development of new diagnostic strategies and drug-targeted therapies for ovarian cancer.
\end{abstract}

\section{Introduction}

Of all gynecological malignancies, ovarian carcinoma accounts for the highest number of cases of mortality in Europe (1), the United States (2), and China (3). The current

Correspondence to: Professor Xiaoqiu Liang, Cancer Research Institute, University of South China, Hengyang, Hunan 421001, P.R. China

E-mail: liangxiaoqiu368@163.com

Key words: peptide, ovarian cancer, targeted therapy, phage display standard of care includes the combination of radical surgery and platinum-based chemotherapy. Among patients who have early-stage cancers, $90 \%$ can be cured using current therapies; however, this percentage declines substantially in patients with advanced disease (4). Approximately $30 \%$ of patients with advanced-stage ovarian carcinoma survive 5 years after the initial diagnosis. Despite prolific drug development, the treatment of ovarian carcinoma is confronted with difficulties, such as metastatic bulky disease burden and stagnant mortality rates (5). Thus, new methods for the early detection of ovarian carcinoma and effective treatment are important.

Targeted therapy is a new treatment strategy that aims to increase tumor selectivity while decreasing the toxic effects on healthy cells. Targeted therapies use specific molecules in tumor tissues as carriers of tumor-targeting drugs to improve anticancer drug delivery, drug-targeting specificity, and safety $(6,7)$. Various antigens and receptors in carcinoma cells that differ from normal cells have been found. Numerous targets exist in ovarian carcinoma cells. The receptors include VEGFR, ER- $\alpha$, ErbB, EGFR, and IGF-1R, among others (8-10). The antigens include CA-125, TAG-72, PEM and Lewis-Y, among others $(11,12)$. Various monoclonal antibodies directed toward specific antigens in patients with ovarian cancer have been reviewed and discussed (13). However, the effect of clinical ovarian cancer treatment is not ideal (14). The lack of an efficient targeting carrier system presents an obstacle to its efficacy.

Peptides have displayed traits that are suitable for diagnosis and targeted treatment. These traits include efficient tissue targeting and low toxicity (15-20). Phage display is a technique that fuses random peptides to the protein coat of a bacteriophage in a manner that makes them accessible to target ligands. The DNA that encodes the peptide sequence is protected within the virion (21). This technology has facilitated significant developments that can be used in the long term. The identified 'homing' peptides are promising alternatives to the currently used biomolecules for targeting metastatic cells due to their rapid blood clearance, increased diffusion and tissue penetration, non-immunogenic nature, and ease of synthesis (19).

The goal of this research was to identify a specific peptide sequence that binds to ovarian cancer cells for the further development of targeted treatment by screening a library of phage-displayed peptides in vivo. These peptides can simulate 
the body environment and maintain the native conformation of various types of ligands on the tissues of interest. In the initial step, a 7-mer library was injected into nude mice through a vein. After three rounds of screening, phages were enriched. Through the detection of the target phage and extraction of the phage DNA test sequence, the specific-binding peptide was derived. The position, distribution and targeting effect of OSTP were also verified in vitro and in vivo. However, differences exist between humans and mice. Thus, human pathologic specimens were used to test the affinity.

\section{Materials and methods}

Cell lines. Human ovarian cancer A2780 cells were provided by the Huazhong University of Science and Technology. Human osteosarcoma MG63 cells were preserved in our laboratory. All cell lines were maintained in complete RPMI-1640 medium containing $10 \%$ fetal bovine serum.

Tissue specimens. The study adhered to the laws of China regarding research and the guidelines approved by the Ethics Committee of the University of South China. Archival paraffinembedded, formalin-fixed specimens of oophoroma tissues, ovarian cystadenoma tissues, other ovarian tumor tissues, ovarian normal tissues, and uterine tissues were obtained from the Pathological Diagnostic Center and The First Affiliated Hospital of the University of South China. All tissue samples were collected at initial diagnosis from January 2009 through December 2012 before treatment, including chemotherapy or radiation.

Construction of the mouse models. Four-week-old BALB/c nu/ nu mice were obtained from Beijing Vital River Laboratories. A single dose of $1 \times 10^{7}$ A 2780 cells was injected s.c. into the posterior trunk to induce tumor formation.

Peptide library screening, FliTrx clone binding and peptide synthesis. A random phage 7-mer peptide display library, FliTrx (New England Biolabs), was screened. Tumor-targeting FliTrx clones were isolated from the FliTrx library using combined in vivo screening according to the manufacturer's instructions. Quantification of binding selectivity was determined by cellbased ELISA. A2780 cells were cultured and plated into a 96-well plate $\left(1 \times 10^{4}\right.$ cells/well) the day before use. Cells were washed, incubated in serum-free RPMI-1640 medium at $37^{\circ} \mathrm{C}$ for $2 \mathrm{~h}$, and then fixed in $4 \%$ paraformaldehyde in phosphatebuffered saline (PBS) for $15 \mathrm{~min}$. Cells were washed thrice with Tris-buffered saline Tween-20 (TBST) and blocked with blocking buffer (TBST contained $3 \% \mathrm{BSA}$ ) at $37^{\circ} \mathrm{C}$ for $1 \mathrm{~h}$. The randomly selected amplified phage clones were each added into the cells at $10^{12} \mathrm{pfu} /$ well, and the plate was incubated at $37^{\circ} \mathrm{C}$ for $1.5 \mathrm{~h}$. Subsequently, unbound phage was removed by washing the plate thrice with TBST. To detect phage binging to the cells, the wells were incubated for $1 \mathrm{~h}$ with $100 \mu \mathrm{l} /$ well of mouse anti-M13 antibody (dilution, 1:5,000 in the blocking buffer). After washing the plate thrice with TBST, $100 \mu \mathrm{l}$ of HRP-conjugated sheep anti-mouse Ig was added to each well (dilution, 1:5,000 in the blocking buffer). Subsequently, color development was induced by adding $100 \mu \mathrm{l} /$ well of freshly prepared diaminobenzidine solution and then incubating the plate for $5 \mathrm{~min}$ at $37^{\circ} \mathrm{C}$. The plates were read on an automated ELISA plate reader at an absorbance of $490 \mathrm{~nm}$. Triplicate determinations were performed at each data point. Selectivity was determined using the following formula: P/N (the positive phage $\mathrm{OD} /$ control phage $\mathrm{OD})>2.1$. The ELISA-positive phage was expanded, and the single-stranded DNA clone sequence was detected. According to the base sequence, the short peptide amino acid sequence was obtained. The OSTP peptide and the control peptide NSTP, the amino acid of which was screened from another research, were detected. Then, 5-FAM was coupled at the $\mathrm{NH}_{2}$ terminus. The peptides were synthesized by Shanghai Sangong Co., and then purified by high-performance liquid chromatography. The sequence and structure of the peptides were confirmed by mass spectrometry.

Cell fluorescence staining. Ovarian cancer A2780 cells and osteosarcoma MG63 cells were cultured at the logarithmic phase for use in the experiment. After pancreatic enzyme digestion and heavy suspension, the cells were adjusted to $2.5 \times 10^{5} / \mathrm{ml}$ and then placed into 6 orifice plates for culture. In the experimental group, $2 \mu \mathrm{l}(4.9 \mathrm{mg} / \mathrm{ml})$ of 5-FAM-OSTP was added, whereas in the control group, $2 \mu \mathrm{l}$ of $50 \%$ DMSO solvent agent was added. The cells were continuously cultured for $16 \mathrm{~h}$ while avoiding light. PBS was used to wash the plates. The cover glasses were removed when the cells were dry. The cells were then fixed with acetone for $15 \mathrm{~min}$, washed, and exposed to antagonize fluorescence quenching agent to seal the pieces. The cells were examined for fluorescence by using laser scanning confocal microscopy (Olympus). Experiments were repeated thrice. The fluorescence distribution of the incubated A2780 cells was observed in different periods, and images were captured.

Tumor targeting. Tumor-bearing mice were used for targeting experiments. The tumors grew to a size of 1.0 to $2.0 \mathrm{~cm}^{3}$. OSTP $(980 \mu \mathrm{g})$ was injected into the tail vein and allowed to circulate for $15 \mathrm{~min}$. The control group was injected with NSTP $(980 \mu \mathrm{g})$ and $20 \%$ DMSO $(980 \mu \mathrm{g})$. The mice were perfused with PBS through the left ventricle to remove blood and unbound peptides. Tumors and control organs were excised, and frozen sections were prepared and examined for fluorescence using laser scanning confocal microscopy. Quantification of the imaging results was accomplished using Image-Pro Plus 6.0.

Affinity of OSTP to ovarian cancer tissues. Human ovarian cancer samples, human ovarian cystadenoma samples, other ovarian tumor samples, human normal ovarian samples, and human uterine samples were sectioned serially at $2 \mu \mathrm{m}$. After drying at $60^{\circ} \mathrm{C}$ from 30 to $60 \mathrm{~min}$, the slides were transferred to xylene I for $20 \mathrm{~min}$, xylene II for $10 \mathrm{~min}, 100 \%$ ethanol for $5 \mathrm{~min}, 95 \%$ ethanol for $5 \mathrm{~min}$, and then $85 \%$ ethanol for $5 \mathrm{~min}$ to be deparaffinized and rehydrated. The slides were then shaken and washed twice for $5 \mathrm{~min}$ with $\mathrm{ddH}_{2} \mathrm{O}$ and twice for $5 \mathrm{~min}$ with PBS. Antigen was retrieved by soaking the slides in pH 6.0 citric acid solution. The slides were blocked in BSA for $30 \mathrm{~min}$ at $37^{\circ} \mathrm{C}$ in a chamber and then in $100 \mu \mathrm{l}$ of 5-FAM-OSTP $(2.0 \mathrm{mg} / \mathrm{ml})$ for $1 \mathrm{~h}$ at $37^{\circ} \mathrm{C}$ in a chamber kept away from light and sealed with a $\mathrm{Na}_{2} \mathrm{CO}_{3}$ and glycerine solution. The slides were then observed, and images were captured 


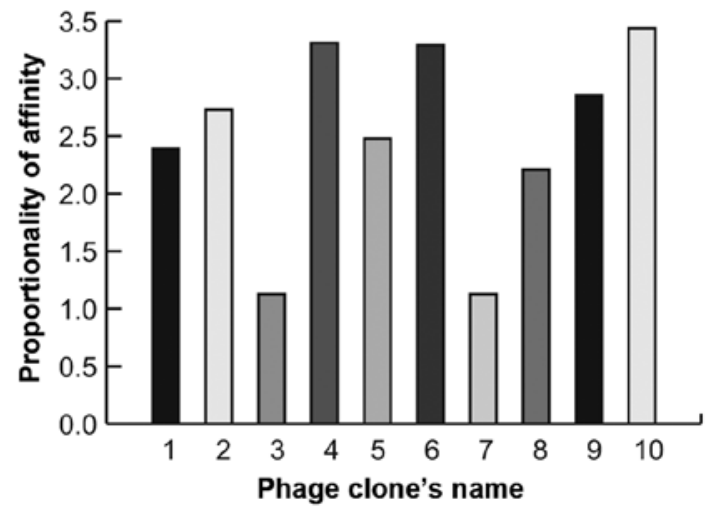

Figure 1. Identification of phage monoclonal affinity to ovarian cancer A2780 cells using cell-based ELISA. 1-10, phage monoclones. Eight phage clones $(1,2,4,5,6,8,9$ and 10$)$ appreared to have the most specific binding ability.

under a fluorescence microscope. The same tissue slides were diagnosed through H\&E staining.

Statistical analysis. Values are expressed as mean \pm SD. The significance of the difference from the respective controls for each experimental test condition was assayed using the Student's t-test for each paired experiment. A p-value of $<0.05$ or 0.01 was considered as indicative of a statistically significant result.

\section{Results}

Identification of a peptide that specifically binds to ovarian cancer cells. Targeting peptides were selected in vivo by screening the FliTrx library with the ovarian carcinoma A2780 cells for three rounds. After each round of screening, the FliTrx concentration in the tumor tissues was significantly increased, whereas that in the control tissues was reduced. After the third round, 10 individual FliTrx clones were selected. To confirm the specific binding of the selected phages to A2780 cells, 10 independent phage clones were randomly selected for testing using cell-based ELISA. To calculate selectivity, the binding of each phage to the A2780 cells was compared with the original library locus coeruleus. The phage optical density ratio of $>2.1$ indicated that specific binding to the A2780 cells had occurred. The results showed that 8 phage clones apparently possessed the most specific binding capability (Fig. 1). The peptide-encoding inserts of these clones were sequenced. One of the peptide sequences (PHLATLF) appeared 8 times in the selected clones.

OSTP specifically binds to ovarian cancer cells in vitro. OSTP and NSTP were synthesized and labeled by 5-FAM from Shanghai Shenggong Co. (purity $>95 \%$ ). The solvent control group of the ovarian cancer A2780 cells did not produce fluorescence (the background is dark). MG63 cells also did not produce spontaneous fluorescence (Fig. 2). However, the ovarian cancer A2780 cell cytoplasm and membrane produced bright yellow-green fluorescence after incubation with 5-FAM-OSTP. The results confirmed that 5-FAM-OSTP has specific combining capability with ovarian cancer A2780 cells, and the binding sites are mainly located on the cell membrane.

OSTP targets ovarian cancer tumors in vivo. First, 5-FAM-OSTP $(980 \mu \mathrm{g}), 5$-FAM-NSTP $(980 \mu \mathrm{g})$, and $20 \%$ DMSO $(980 \mu \mathrm{g})$ were injected into the tail vein of the mice and allowed to circulate for $15 \mathrm{~min}$ in each group. Second, tumors and control organs were excised and processed for frozen sectioning. The 5-FAM-OSTP specifically targeted tumors. In the liver and kidney very weak fluorescence was observed, whereas in other control organs, no visible fluorescence was observed (Fig. 3). As shown in Fig. 4, the results of the analysis of the average fluorescence intensity of organs using ImageJ software are shown. Compared with other tissues, the fluorescent intensity in tumor tissues was significantly higher $(\mathrm{P}<0.01)$.
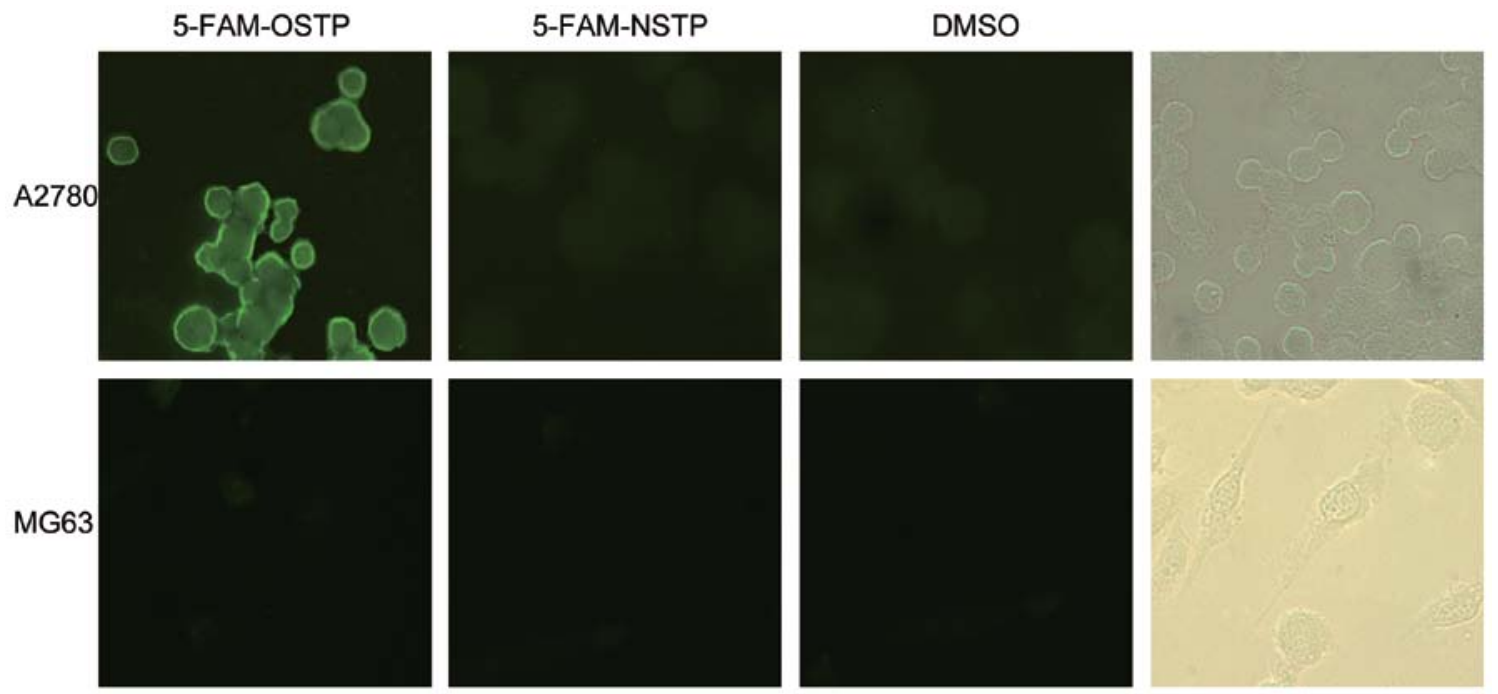

Figure 2. Affinity and specificity of 5-FAM-OSTP to ovarian cancer A2780 cells (magnification, x200). The A2780 cell cytoplasm and membrane produced bright yellow-green fluorescence after incubation with 5-FAM-OSTP. 

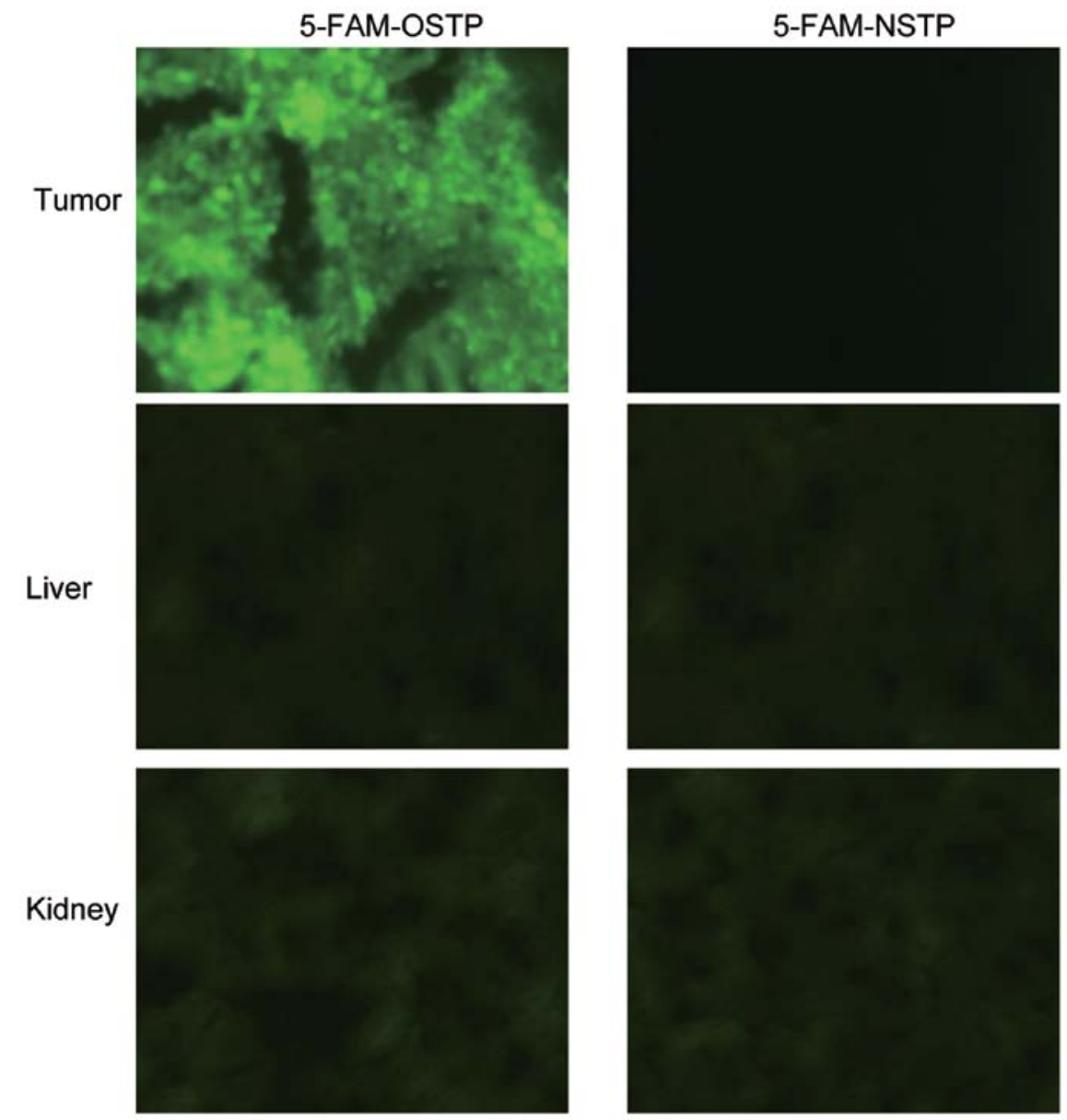

Figure 3. Fluorescent signal of 5-FAM-OSTP in the A2780 tumor-bearing mice (magnification, $\mathrm{x} 200$ ). The fluorescent signal was very strong in the tumor tissues, with extremely weak staining in the liver and kidney.

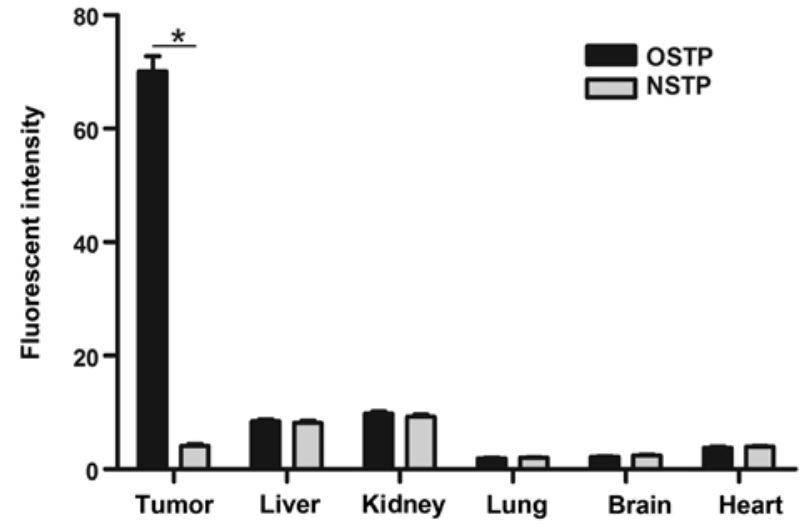

Figure 4. Graph of the fluorescent intensity in the organs of the A2780 tumor-bearing mice. Compared with other tissues, the level of fluorescent intensity in the tumor tissues was significantly higher $\left({ }^{*} \mathrm{P}<0.01\right)$.

OSTP specifically binds to human ovarian cancer specimens. Yellow-green fluorescence was observed in the ovarian cancer tumor tissues. The fluorescence was brighter at the cell membrane and weaker in the cytoplasm. Very weak background fluorescence was observed in tumor stroma. 5-FAM-OSTP may specifically combine with ovarian cancer tissues that express various antigens. However, 5-FAM-OSTP did not combine with the endometria and uterine wall. 5-FAM-OSTP did not combine with other human ovarian tumors, ovarian cystadenoma and normal ovarian tissues (Fig. 5 and Table I).

\section{Discussion}

Ovarian cancer remains a challenge for clinical treatment. The disease is incurable for the majority of patients due to relapse attributed to resistance to chemotherapeutic drugs (22). The typically used chemotherapeutic drugs are carboplatin and paclitaxel. Novel drugs for targeted therapy are needed to reduce drug resistance and severe side effects, which are mainly caused by the non-cancer cell specificity of the agents and the insensitivity of cancer cells. Different avenues have been pursued to achieve this goal (23).

Since 1990, the phage display has been successfully constructed, and peptide libraries have been widely applied for the in vivo and in vitro screening for research on target enzymes, carbohydrates, receptors, antibodies and nucleic acids (24). A wide variety of tumor-specific binding peptides have been discovered through the phage display. These peptides include RGD-4C, NGR, CPRECES and GSL, which can target tumor vascular endothelium (25-27). Pasqualini and colleagues $(28,29)$ were the first to screen peptides that combined specifically to the brain and kidney. They successfully screened another short peptide that included the RGD 

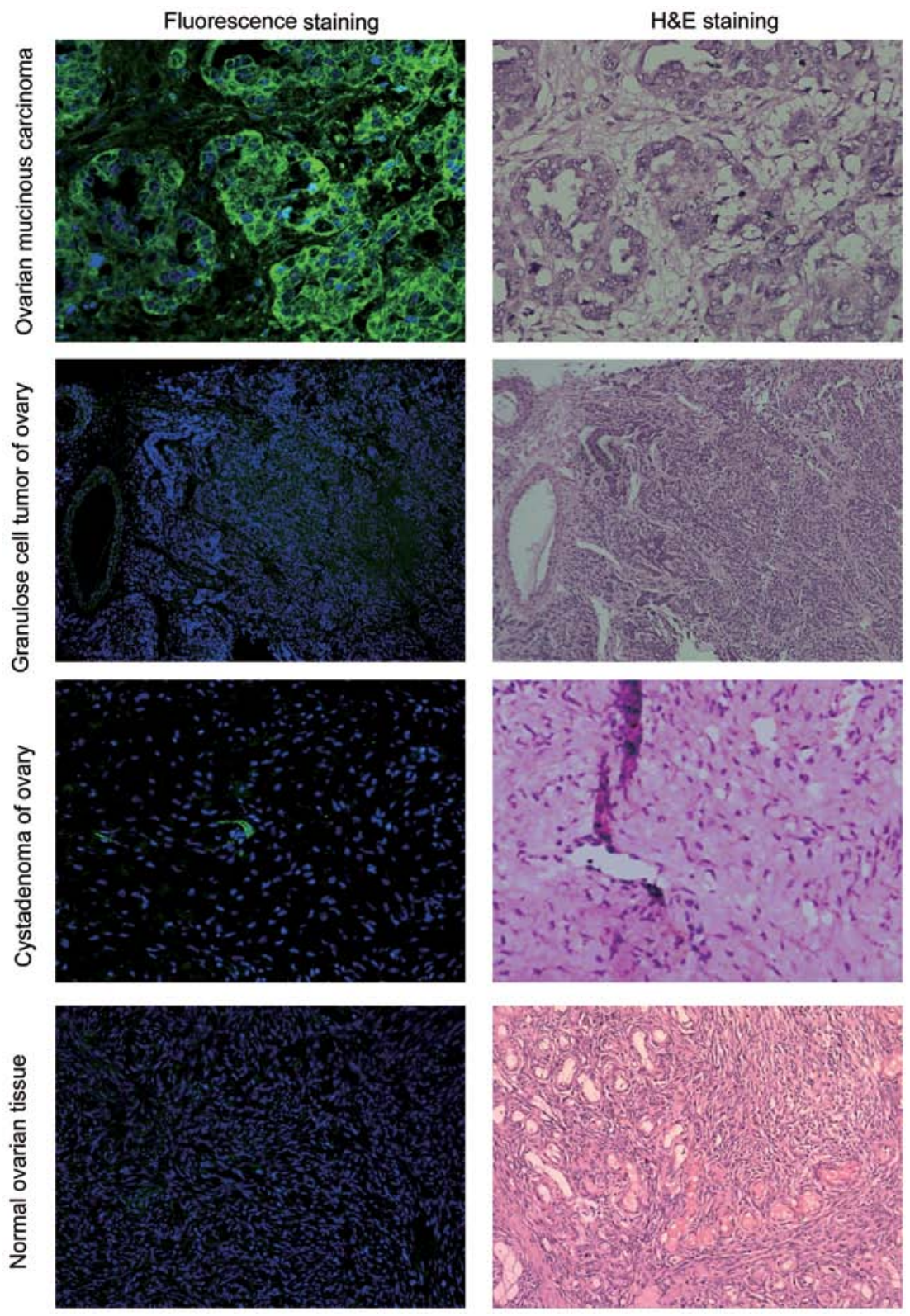

Figure 5. 5-FAM-OSTP fluorescence and H\&E staining in the different tissues. Yellow-green fluorescence was observed in the ovarian cancer tissues. No fluorescence was observed in the tumor stroma and other tissues.

Table I. Fluorescent signal of 5-FAM-OSTP in ovarian carcinoma tissues.

\begin{tabular}{lcc} 
Type of tissue & Total no. & $\begin{array}{c}\text { Cases with positive } \\
\text { fluorescence }\end{array}$ \\
\hline Ovarian carcinoma & 38 & 33 \\
Non-epithelial ovarian & 12 & 2 \\
malignant tumor & 11 & 1 \\
Cystadenoma of the ovary & 10 & 1 \\
Normal ovarian & &
\end{tabular}

sequence, which can specifically bind to malignant melanoma and breast cancer integrin $\alpha$ (subunit v). By using phage display technology, a short peptide binding specifically to tumor vasculature was selected as a drug carrier of adriamycin for the targeted therapy of breast tumor-bearing mice in vivo with superior effects (30). Teesalu et al (31) found that tumorpenetrating peptides can bind to the NRP-1 protein, thereby significantly improving the drug penetration capability by increasing tumor accumulation. The use of targeted peptides has made significant progress in recent years. Yang et al (19) detected a novel tumor-homing peptide that specifically targets metastasis. The specific-binding peptide A54, which was screened from a phage display library, represents a promising approach for the development of novel targeted therapeutic strategies against hepatocellular carcinoma. The affinity peptide was discovered for targeted detection of dysplasia in Barrett's esophagus (18). OA02 peptide-targeted polymeric micelle system was developed for effective paclitaxel delivery in an ovarian cancer xenograft mouse model (32). Li et al (33) utilized a pro-apoptotic peptide conjugated to a Toll-like receptor and two mediated cell-penetrating peptides that target 
acute myeloid leukemia. A large number of peptide complexes are under further study. The use of a phage display for peptide selection shows great potential for recognizing specific targets.

In the present study, OSTP with specific affinity to ovarian cancer in vitro and in vivo was demonstrated in different assays. Three rounds of screening in nude mice were conducted. After the third round of screening, the peptide sequence (PHLTALF) appeared 8 times in ELISA, thus illustrating that the short peptide has an effective concentration in vivo. A random peptide library contained the same specific fragment of phage. Thus, OSTP exhibited tissue-specific affinity. During the input of the first round of screening, the phage library was $2.0 \times 10^{11} \mathrm{pfu}$, thus ensuring that tens of thousands of short peptide sequences contained the short peptide in the ovarian cancer cell cytoplasm and membrane, in which some antigens that specifically bind to OSTP are present. High affinity to tumor tissues was observed after circling in vivo. The tumor tissues exhibited a strong fluorescence signal. Meanwhile, the control organs exhibited no visible fluorescence signal.

Identifying the receptor that binds to OSTP on the cell surface is important for better understanding of the molecular properties of OSTP. We are conducting further research to isolate the OSTP receptor. Affinity chromatography and timeof-flight delayed extraction MALDI mass spectrometry is being used for this purpose.

Moreover, OSTP was investigated using clinical tissue samples of ovarian cancer due to the differences between human ovarian cancer tissues from the cells cultured in vitro and simulative animal models. According to the immunofluorescence technique, meaningful results were obtained. Immunofluorescence results demonstrated yellow-green fluorescence in the human ovarian cancer tissues. The fluorescence was mainly present on the cell membranes, whereas the stroma exhibited only weak background fluorescence. Ovarian cystadenoma, other ovarian tumors, and contrast uterine tissues did not show an obvious yellow-green fluorescent signal. The results demonstrated that OSTP has specificity for human ovarian cancer tissues.

Therefore, OSTP may be applied as a new ovarian cancer screening biomarker and a new targeting carrier that can be coupled with chemotherapy drugs. The peptide structure must be modified to improve stability in vivo and to increase water solubility so that when combined with a drug, the antitumor activity of the compound can be detected in ovarian cancer cells. Moreover, the anticancer therapeutic effect on ovarian cancer-bearing mice can be confirmed, and the pharmacokinetics of compound cycling in tumor-bearing mice can be studied. OSTP appears to be a useful tool for targeted treatment and diagnosis of ovarian cancer.

\section{Acknowledgements}

This study was supported by grants from the National Science Foundation of China (no. 81101988).

\section{References}

1. Gondos A, Bray F, Hakulinen T and Brenner H; EUNICE Survival Working Group: Trends in cancer survival in 11 European populations from 1990 to 2009: A model-based analysis. Ann Oncol 20: 564-573, 2009 .
2. Jemal A, Siegel R, Ward E, Hao Y, Xu J, Murray T and Thun MJ: Cancer statistics, 2008. CA Cancer J Clin 58: 71-96, 2008.

3. Yang NN, Yan YQ and Gong J: An analysis on incidence and mortality of ovarian cancer from 2003 to 2007 in China. China Cancer 21: 401-405, 2012.

4. Yang D, Sun Y,Hu L, Zheng H, Ji P, Pecot CV, Zhao Y, Reynolds S, Cheng H, Rupaimoole R, et al: Integrated analyses identify a master microRNA regulatory network for the mesenchymal subtype in serous ovarian cancer. Cancer Cell 23: 186-199, 2013.

5. Coleman RL, Monk BJ, Sood AK and Herzog TJ: Latest research and treatment of advanced-stage epithelial ovarian cancer. Nat Rev Clin Oncol 10: 211-224, 2013.

6. Zhu AX and Hezel AF: Development of molecularly targeted therapies in biliary tract cancers: Reassessing the challenges and opportunities. Hepatology 53: 695-704, 2011.

7. Masoumi Moghaddam S, Amini A, Morris DL and Pourgholami MH: Significance of vascular endothelial growth factor in growth and peritoneal dissemination of ovarian cancer. Cancer Metastasis Rev 31: 143-162, 2012.

8. Ferrara N, Gerber HP and LeCouter J: The biology of VEGF and its receptors. Nat Med 9: 669-676, 2003.

9. Bookman MA, Darcy KM, Clarke-Pearson D, Boothby RA and Horowitz IR: Evaluation of monoclonal humanized anti-HER2 antibody, trastuzumab, in patients with recurrent or refractory ovarian or primary peritoneal carcinoma with overexpression of HER2: A phase II trial of the Gynecologic Oncology Group. J Clin Oncol 21: 283-290, 2003.

10. Tebbutt N, Pedersen MW and Johns TG: Targeting the ERBB family in cancer: Couples therapy. Nat Rev Cancer 13: 663-673, 2013.

11. Morotti M, Valenzano Menada M, Venturini PL, Mammoliti S and Ferrero S: Pemetrexed disodium in ovarian cancer treatment. Expert Opin Investig Drugs 21: 437-449, 2012.

12. Oei AL, Sweep FC, Thomas CM, Boerman OC and Massuger LF: The use of monoclonal antibodies for the treatment of epithelial ovarian cancer (Review). Int J Oncol 32: 1145-1157, 2008.

13. Leone Roberti Maggiore U, Bellati F, Ruscito I, Gasparri ML, Alessandri F, Venturini PL and Ferrero S: Monoclonal antibodies therapies for ovarian cancer. Expert Opin Biol Ther 13: 739-764, 2013.

14. Siegel R, Ward E, Brawley O and Jemal A: Cancer statistics, 2011: The impact of eliminating socioeconomic and racial disparities on premature cancer deaths. CA Cancer J Clin 61: 212-236, 2011.

15. Corso S, Ghiso E, Cepero V, Sierra JR, Migliore C, Bertotti A, Trusolino L, Comoglio PM and Giordano S: Activation of HER family members in gastric carcinoma cells mediates resistance to MET inhibition. Mol Cancer 9: 121, 2010.

16. Smith GP: Filamentous fusion phage: Novel expression vectors that display cloned antigens on the virion surface. Science 228: 1315-1317, 1985 .

17. Wang N, Thuraisingam T, Fallavollita L, Ding A, Radzioch D and Brodt P: The secretory leukocyte protease inhibitor is a type 1 insulin-like growth factor receptor-regulated protein that protects against liver metastasis by attenuating the host proinflammatory response. Cancer Res 66: 3062-3070, 2006.

18. Li M, Anastassiades CP, Joshi B, Komarck CM, Piraka C, Elmunzer BJ, Turgeon DK, Johnson TD, Appelman H, Beer DG, et al: Affinity peptide for targeted detection of dysplasia in Barrett's esophagus. Gastroenterology 139: 1472-1480, 2010.

19. Yang W, Luo D, Wang S, Wang R, Chen R, Liu Y, Zhu T, Ma X, Liu R, Xu G, et al: TMTP1, a novel tumor-homing peptide specifically targeting metastasis. Clin Cancer Res 14: 5494-5502, 2008.

20. Sugahara KN, Teesalu T, Karmali PP, Kotamraju VR, Agemy L, Girard OM, Hanahan D, Mattrey RF and Ruoslahti E: Tissue-penetrating delivery of compounds and nanoparticles into tumors. Cancer Cell 16: 510-520, 2009.

21. Noren KA and Noren CJ: Construction of high-complexity combinatorial phage display peptide libraries. Methods 23: 169-178, 2001.

22. Bamias A, Pignata S and Pujade-Lauraine E: Angiogenesis: A promising therapeutic target for ovarian cancer. Crit Rev Oncol Hematol 84: 314-326, 2012.

23. Vosjan MJ, Vercammen J, Kolkman JA, Stigter-van Walsum M, Revets $\mathrm{H}$ and van Dongen GA: Nanobodies targeting the hepatocyte growth factor: Potential new drugs for molecular cancer therapy. Mol Cancer Ther 11: 1017-1025, 2012.

24. Zwick MB, Shen J and Scott JK: Phage-displayed peptide libraries. Curr Opin Biotechnol 9: 427-436, 1998.

25. Ferrara $\mathrm{N}$ and Kerbel RS: Angiogenesis as a therapeutic target. Nature 438: 967-974, 2005. 
26. Brooks PC, Montgomery AM, Rosenfeld M, Reisfeld RA, Hu T, Klier G and Cheresh DA: Integrin alpha v beta 3 antagonists promote tumor regression by inducing apoptosis of angiogenic blood vessels. Cell 79: 1157-1164, 1994.

27. Li XB, Schluesener HJ and Xu SQ: Molecular addresses of tumors: Selection by in vivo phage display. Arch Immunol Ther Exp (Warsz) 54: 177-181, 2006.

28. Pasqualini R and Ruoslahti E: Organ targeting in vivo using phage display peptide libraries. Nature 380: 364-366, 1996.

29. Pasqualini R, Koivunen E and Ruoslahti E: Alpha v integrins as receptors for tumor targeting by circulating ligands. Nat Biotechnol 15: 542-546, 1997.

30. Arap W, Pasqualini R and Ruoslahti E: Cancer treatment by targeted drug delivery to tumor vasculature in a mouse model. Science 279: 377-380, 1998.
31. Teesalu T, Sugahara KN, Kotamraju VR and Ruoslahti E: C-end rule peptides mediate neuropilin-1-dependent cell, vascular, and tissue penetration. Proc Natl Acad Sci USA 106: 16157-16162, 2009.

32. Xiao K, Li Y, Lee JS, Gonik AM, Dong T, Fung G, Sanchez E, Xing L, Cheng HR, Luo J, et al: 'OA02' peptide facilitates the precise targeting of paclitaxel-loaded micellar nanoparticles to ovarian cancer in vivo. Cancer Res 72: 2100-2110, 2012.

33. Li K, Lv XX, Hua F, Lin H, Sun W, Cao WB, Fu XM, Xie J, Yu JJ, Li Z, et al: Targeting acute myeloid leukemia with a proapoptotic peptide conjugated to a toll-like receptor 2-mediated cell-penetrating peptide. Int J Cancer 134: 692-702, 2014. 